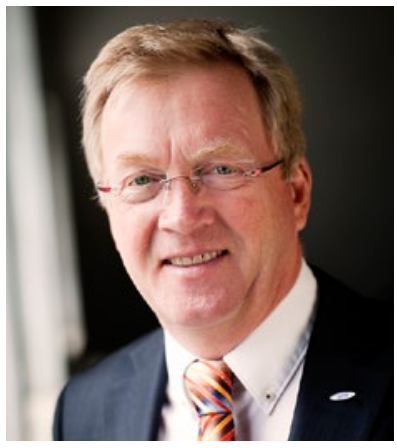

Andreas Westerfellhaus

Präsident des

Deutschen Pflegerats (DPR)
Deutscher Pflegerat e.V.

Bundesarbeitsgemeinschaft

Pflege- und Hebammenwesen

In Kooperation mit

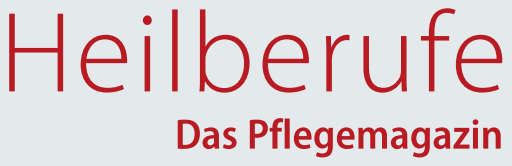

\title{
Editorial
}

\section{Tarifvertrag als Blaupause}

$\mathrm{N}$ ach jahrelangen Auseinandersetzungen haben sich die Charité - Universitätsmedizin Berlin und die Dienstleistungsgewerkschaft ver.di auf einen Tarifvertrag geeinigt. Mit den bis jetzt bundesweit einmaligen Vereinbarungen zur personellen Mindestbesetzung in der Intensivpflege, Kinderklinik und stationären Krankenpflege wird es gelingen, die Arbeitsbedingungen im Krankenhaus wesentlich zu verbessern. Der Deutsche Pflegerat fordert alle Krankenhäuser in Deutschland auf, diesen Tarifabschluss als Blaupause für ihre Personalpolitik zu nehmen.

In dem Tarifvertrag stehen Gesundheitsschutz und die Gesundheitsprävention für die im Krankenhaus beschäftigten Pflegenden an erster Stelle. Das ist ein klares Signal gegen eine immer weitere körperliche und seelische Mehrbelastung der professionell Pflegenden. Zudem ist künftig klar, welcher Personalmindeststandard in der Pflege in der Charité gilt. Einen großflächigen Personalabbau, wie es diesen in der Vergangenheit gegeben hat, ist zumindest für die Charité ausgeschlossen. Der Vertrag zeigt, dass sich der Einsatz der professionell Pflegenden für bessere Arbeitsbedingungen - bis hin zum Streik - gelohnt hat. Das gibt uns Mut für die Zukunft. Die Fremdbestimmung über die Berufe in der Pflege muss ein Ende haben. Der jetzt beschlossene Tarifvertrag darf jedoch nicht darüber hinwegtäuschen, dass in den letzten Jahren 50.000 Vollzeitstellen im Pflegedienst im Krankenhaus abgebaut worden sind. Die Finanzierung des Pflegepersonals ist nach wie vor nur ungenügend geklärt.

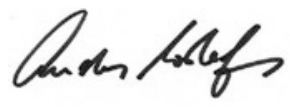

Andreas Westerfellhaus

Präsident des Deutschen Pflegerats (DPR)

\section{IM FOCUS}

\section{Arbeit nicht in Verruf bringen}

Das Bundeskriminalamt hat auf systematische Betrügereien von bestimmten Pflegediensten in der Pflege hingewiesen. Das mediale Echo war enorm. Auch Bundesgesundheitsminister Hermann Gröhe hat unmittelbar reagiert. Im Rahmen eines Spitzengespräches hat er den Deutschen Pflegerat und weitere maßgebliche Institutionen des Pflege- und Gesundheitsbereichs zu einem Meinungsaustausch eingeladen. Aus Sicht des Deutschen Pflegerats ist es erschütternd, in welchem Maß hier betrügerisch vorgegangen wurde und wird. Jede Form des Missbrauchs ist massiv und mit allen zur Verfügung stehenden Mitteln zu ahnden. Dies heißt jedoch nicht, für die gesamte Pflegebranche reflexartig neue und weitere Kontrollen einzuführen. Es geht darum, ganz gezielt dort anzusetzen und energisch zu prüfen, wo Missbrauch vorliegt. Hier ist in die Tiefe zu gehen, schonungslos aufzudecken und konsequent zu bestrafen.

Die Pflegebedürftigen und deren Angehörige müssen sich darauf verlassen können, dass gute Pflege geleistet wird. Die Beschäftigten in der Pflege müssen sich gleichfalls darauf verlassen können, dass ihre wertvolle Arbeit nicht durch die Machenschaften einzelner Betrüger in Verruf gebracht wird.

Der DPR unterstützt daher die Initiative von Bundesgesundheitsminister Gröhe, die Aktivitäten zur Bekämpfung und Vermeidung von Betrügereien stärker miteinander zu verzahnen und - da, wo es notwendig ist - nicht nur gezielt zu kontrollieren oder zu ermitteln, sondern gegebenenfalls auch neues Recht zu setzen.

\section{Thomas Meißner}

Mitglied des Präsidiums des

Deutschen Pflegerats 